\title{
Prevalence and Antibiogram of Generic Enterococci in Ready-to-Slaughter Beef Cattle
}

\author{
Madubuike U. ANYANWU ${ }^{1 *}$, Timothy U. OBETTA ${ }^{2}$ \\ ${ }^{I}$ University of Nigeria, Microbiology Unit, Department of Veterinary Pathology and Microbiology, Nsukka, \\ Nigeria;madubuike.anyanun@unn.edu.ng("corresponding author) \\ ${ }^{2}$ University of Nigeria, Faculty of Veterinary Medicine, Department of Veterinary Pathology and Microbiology, Nsukka, \\ Nigeria; ugochukurtimothy385@yahoo.com
}

\begin{abstract}
Rectal swabs were collected from 95, systematic randomly selected, apparently healthy beef cattle, in order to isolate generic enterococci in Nsukka Southeast, Nigeria, and thus to determine the antibacterial resistance profile of the isolates. Isolation of enterococci was done using Slanetz-Bartley enterococci selective medium. Phenotypic characterization of the isolates to generic level was done following standard biochemical methods. Phenotypic resistance of the isolates to antibacterial agents was determined using the disc diffusion method. From 95 swabs, 93 (97.89\%) were positive for enterococci. Of the 93 isolates, 10 (10.75\%) were haemolytic Enterococcus species, while 83 (89.25\%) were non-haemolytic Enterococcus species. Out of 75 isolates, all (100\%) were resistant to cefoxitin, 66 (88\%) were resistant to ampicillin, 71 (94\%) to amoxicillin/clavulanic acid, 68(90.7\%) to ceftriaxone, 42 $(56 \%)$ to streptomycin, $74(98.67 \%)$ to gentamicin, $16(21.3 \%)$ to tetracycline, $5(6.7 \%)$ to vancomycin, 62 (82.7\%) to sulphamethoxazole/trimethoprim, and 1 (1.3\%) to chloramphenicol and ciprofloxacin. None of the isolate was resistant to imipenem. The enterococcal isolates exhibited 22 resistance patterns. Out of 75 isolates, 1 (1.3\%) isolate was resistant to 1 class of antibacterial agents, 9 (12\%) were resistant to 2 classes, and $65(86.7 \%)$ to 3 or more classes. This study has shown that cattle slaughtered in Nsukka Southeast Nigeria are potential reservoirs and disseminators of multidrug-resistant enterococci.
\end{abstract}

Keywords: antibiogram, enterococci, multidrug resistant, bovine

Abbreviations: Ampicillin-AMP, Amoxicillin/clavulanic acid-AMC, Streptomycin-STP, Gentamicin-GEN, Cefoxitin-CEF, Ceftriaxone-CTR, Sulfamthoxazole/trimethoprim-SXT

\section{Introduction}

Currently, one of the greatest challenges/threats facing mankind is antimicrobial resistance as it constitutes health crisis (WHO, 2014). Although antibacterial resistance is a natural phenomenon for microbial adaptation, acquired resistance evolved following inappropriate use of antimicrobials in human and veterinary medicine (Tenover, 2006; Laxminarayan et al., 2013). Developing countries, particularly the African countries, including Nigeria, are important regions for emergence of antimicrobial-resistant organisms. This is due to lack or lax control of antimicrobial use in these countries (Laxminarayan et al., 2013; Martins et al., 2015). It has been observed that many antimicrobial-resistant commensal/indicator organisms enter the food chain undetected, because these organisms, especially the non-clinical isolates, are often neglected (WHO, 2014; Morrison and Rubin, 2015). The one health oriented approach for antimicrobial resistance surveillance involved monitoring the spread of resistance among non-clinical isolates of commensal organisms in food-producing animals (WHO, 2014). Enterococci are ubiquitous Gram-positive catalase-negative organisms, part of normal commensal flora in the gastrointestinal tract of humans and animals (Tremblay et al., 2011; Werner et al., 2013; Beukers et al., 2015). They are also commonly found in the soil, water and other environments (Silva et al., 2012; Klibi et al., 2014). Reports showed considerable diversity in enterococcal strains isolated from food-producing animals, both major $(E$. faecalis and E. faecium) and minor species (such as E. mundtii, E. gallinarum, $E$. durans, E. cassealiflavus, $E$. hirae etc.) have been reported (Nam et al., 2010; Wener et al., 2013; Li et al., 2014, Iweriebor et al., 2015). For long time, the potential of enterococci as pathogens and reservoirs of antimicrobial resistance genes (ARGs) was neglected or underestimated (Sood et al., 2008); they were considered non-pathogenic commensals, the reason for their widespread use as probiotics and food preservatives (Krocko et al., 2007; Werner et al., 2013). By the time their pathogenic potential and capacity to habour ARGs became evident, interest aroused, and all enterococcal species were found to be opportunistic pathogens and to habour variety of ARGs (Nam et al., 2010; Werner et al., 2013).

Contamination of animal carcasses with antimicrobialresistant enterococci is often unavoidable due to the ubiquitous nature of the organisms and their ability to adapt to varying environmental conditions (Huys et al., 2004; Krocko et al., 2011; 
Tremblay et al., 2011). This situation is worse in developing nations, including Nigeria, because unhygienic measures are employed during animal slaughter (Ugwu et al., 2015). Meat contamination with antimicrobial-resistant enterococci constitutes adverse impact on the food chain, and poses threat to public health following direct and indirect contact with and consumption of contaminated meat and associated meat products (Donabedian et al., 2003; McGowan et al., 2006; Hammerum et al., 2010; Werner et al., 2013). Evidences support zoonotic transmission of antimicrobial-resistant enterococci (Stobberingh et al., 1999; Donabedian et al., 2003; Nam et al., 2010; Werner et al., 2013). Significantly, enterococci are among the leading causes of nosocomial and community-acquired infections worldwide (Kuhn et al., 2000; Manolopoulou et al., 2003; Jackson et al., 2010; Werner et al., 2013; Beukers et al., 2015), a capacity attributed to their intrinsic resistance to many classes of antimicrobial agents ( $\mathrm{Li}$ et al., 2014), and worsened by acquisition of multiple resistance genes (Hayes et al., 2004; McGowan et al., 2006; Nam et al., 2010). Most enterococcal isolates from humans and food-producing animals are multidrug resistant strains (Ruzauskas et al., 2009). This underlines the widely reported compromise and complication in antimicrobial therapy often observed in treating enterococcal-associated infections (Vergis et al., 2001; Hershberger et al., 2005; Li et al., 2014; Kilonzo-Nthenge et al., 2015).

There are calls for increased monitoring of the extent of antimicrobial resistance in enterococci harboured by foodproducing animals (Jackson et al., 2010; Ristori et al., 2012; WHO, 2014). Enterococcus species of human, veterinary, and food origin have been used as indicators of occurrence and transfer of antimicrobial resistance (Bager et al., 1998; Kuhn et al., 2000; Nam et al., 2010). They provide accurate information on previous exposure to antimicrobial agents (Nam et al., 2010). Isolation of antimicrobial-resistant enterococci from foods of animal origin raised questions regarding the occurrence of antimicrobial-resistant enterococci in food-producing animals (Borgen et al., 2001; Hayes et al., 2003; Šustáčková et al., 2004; McGowan et al., 2006; Krocko et al., 2007; Koulman et al., 2009; Krocko et al., 2011). There is increasing numbers of reports on isolation of antimicrobial-resistant enterococci from food-producing animals in the last decennium (Anderson et al., 2008). Determination of antibiogram of enterococcal isolates from food-producing animals is essential for monitoring the spread of resistance in food-borne bacteria (Jackson et al., 2010; Ugwu et al., 2015b). This helps in evaluation of trends and identification of mitigation strategies including empirical treatment of infections associated with the organisms (Ugwu et al., 2015b). Surveillance studies to screen food-producing animals as potential reservoirs and disseminators of antimicrobial-resistant enterococci have been conducted in America (Hershberger et al., 2005; Anderson et al., 2008), and some countries in Asia (Stobberingh et al., 1999; Seo et al., 2005; Shin et al., 2006; Han et al., 2011; Li et al., 2014), Europe (Aarestrup et al., 2000; 2002; Kaszanyitzky et al., 2007; Kempf et al., 2008; Brtkova et al., 2010; Kasimoglu-Dogru et al., 2010; Trembley et al., 2011) and Africa (Klibi et al., 2014; Iweribor et al., 2015) Unfortunately, there is paucity of information on occurrence of antimicrobial-resistant enterococci in foodproducing animals in Nigeria. Three reports (David, 2014; Amaechi and Nwankwo, 2015; Amaechi 2015) on antimicrobial-resistant enterococci in food-producing animals in Nigeria, exist in available literature. Moreover, no study has been conducted to screen beef cattle slaughtered in Southeast, Nigeria, whereas cattle is the main source of animal protein for the Nigeria populace. Thus, there is need to screen beef cattle slaughtered in Southeast, Nigeria to determine if they are reservoirs of antimicrobial-resistant enterococci. The objectives of this study, therefore, were to isolate enterococci from ready-toslaughter beef cattle in Nsukka Southeast, Nigeria and determine the antimicrobial resistance profile of the isolates.

\section{Materials and Methods}

\section{Sampling}

Cattle meant for slaughter at Nsukka abattoir between April and June 2015 were sampled. Ninety five beef cattle consisting $10 \%$ of total slaughter within the period of the study were selected using a 1 in 5 systematic random sampling technique. Prior to slaughter, rectal swab was collected from each of the cattle using sterile swab stick. The samples were transported aseptically and processed within 1 hour of collection in the Veterinary Microbiology Laboratory, Department of Veterinary Pathology and Microbiology, University of Nigeria.

\section{Isolation of enterococci}

The swabs were aseptically inoculated into brain heart infusion broth supplemented with $6.5 \%$ sodium chloride and incubated at $37^{\circ} \mathrm{C}$ for 48 hours aerobically. A loopful of the cultures was sub-cultured onto Slanetz-Bartley agar and incubated at $37^{\circ} \mathrm{C}$ for 48 hours aerobically, for selective isolation of enterococci. Pinkish, reddish or maroon-coloured tiny colonies were taken as presumptive enterococci. Purification of the isolates was done by sub-culturing on nutrient agar plates and incubated at $37^{\circ} \mathrm{C}$ for 48 hours. Pure cultures of the isolates were then inoculated onto nutrient agar slants, incubated at 37 ${ }^{\circ} \mathrm{C}$ for 48 hours and stored in refrigerator at $4{ }^{\circ} \mathrm{C}$ as stock cultures until needed for further analysis. Phenotypic characterization of the isolates to generic level was done by subjecting them to various tests such as Gram staining, catalase, bile aesculin, growth at $45^{\circ} \mathrm{C}$ and haemolytic test following standard methods.

\section{Determination of antibiogram of enterococcal isolates from beef} cattle

Antibacterial resistance/susceptibility of 75 enterococcal isolates was determined by the disc diffusion method (CLSI, 2012). The isolates were sub-cultured on nutrient agar, incubated at $37^{\circ} \mathrm{C}$ for 24 hours. Then colonies of each of the isolate were adjusted to $0.5 \mathrm{McF}$ arland's turbidity standard (equivalent to $1 \times 10^{8}$ colony forming unit $/ \mathrm{ml}$ ) in sterile nutrient broth. The standardized broth cultures were incubated for 10 minutes at $37{ }^{\circ} \mathrm{C}$ and then inoculated onto sterile MuellerHinton agar plates using sterile swab stick. Twelve antibacterial agents (Oxoid) belonging to 7 classes were used and they included: ciprofloxacin $(5 \mu \mathrm{g})$, ampicillin $(10 \mu \mathrm{g})$, ceftriaxone (30 $\mu \mathrm{g})$, cefoxitin $(30 \mu \mathrm{g})$, amoxicillin/clavulanic acid $(30 \mu \mathrm{g})$, imipenem $(10 \mu \mathrm{g})$, sulphamethoxazole/trimethoprim (25 $\mu \mathrm{g})$, chloramphenicol (30 $\mathrm{g})$, gentamicin $(30 \mu \mathrm{g})$, streptomycin (10 $\mu \mathrm{g})$, vancomycin $(5 \mu \mathrm{g})$ and tetracycline $(30 \mu \mathrm{g})$. The discs were placed strategically on the inoculated Mueller-Hinton agar plate. The plates were incubated at $37{ }^{\circ} \mathrm{C}$ for 24 hours. After incubation, the zone of inhibition around each disc was measured with a meter rule. Each test was performed in triplicate and the mean inhibitory zone diameter (IZD) calculated to the 
392

nearest whole millimeters for each isolate and each antibacterial agent. The IZD was interpreted as susceptible, intermediate or resistant according to the Clinical and Laboratory Standards Institute (CLSI) (2012) criteria for aerobic isolates.

\section{Results}

\section{Prevalence of generic enterococcal isolates from beef cattle}

Out of 95 rectal swabs cultured, 93 (97.89\%) yielded positive growth (Fig. 1). Of the 93 isolates, 10 (10.75\%) were haemolytic Enterococcus species while 83 (89.25\%) were non-haemolytic Enterococcus species.

\section{Antibiogram of enterococcal isolates from cattle}

Out of 75 isolates, all (100\%) were resistant to cefoxitin, 66 (88\%) were resistant to ampicillin, 71 (94\%) to amoxicillin/clavulanic acid, 68 (90.7\%) to ceftriaxone, $42(56 \%)$ to streptomycin, $74(98.67 \%)$ to gentamicin, $16(21.3 \%)$ to tetracycline, $5(6.7 \%)$ to vancomycin, $62(82.7 \%)$ to sulphamethoxazole/trimethoprim, and 1 (1.3\%) to chloramphenicol and ciprofloxacin. None of the isolate was resistant to imipenem (Fig. 2). The enterococcal isolates exhibited 22 resistance patterns with AMP-AMC-STP-GENCEF-CTR-SXT being the most dominant pattern (Table 1). Out of 75 isolates, $1(1.3 \%)$ isolate was resistant to 1 class of antibacterial agents, $9(12 \%)$ were resistant to 2 classes, and 65 (86.7\%) to 3 or more classes (Fig. 3).

\section{Discussion}

The enterococcal isolation prevalence of $97.89 \%$ recorded in this study, suggested that Slanetz and Bartley's agar could be a highly sensitive medium for selective isolation of enterococci from rectal swabs obtained from food-producing animals (Klibi et al., 2014). It also suggested that almost all the beef cattle slaughtered in the study area harboured enterococci in their gastrointestinal tract. Isolation of $83(89.25 \%)$ non-haemolytic enterococcal strains against $10(10.75 \%)$ haemolytic strains in this study, suggested that non-haemolytic species of Enterococcus may be the dominant strains associated with beef cattle slaughtered in the study area. This finding may be attributed to the health status of the animals. The haemolytic isolates in this study may belong to $E$. faecium, $E$. faecalis, $E$. hirae and $E$. casseliflavus which have been reported to colonize gastrointestinal tract of cattle (Anderson et al., 2008; Jackson et al., 2010; Werner et al., 2013; Beukers et al., 2015), while the non-haemolytic isolates may belong to non-haemolytic enterococcal species such as E. gallinarum and E. mundtii also reported to be endogenous in cattle (Nam et al., 2010; Klibi et al., 2014). Therefore, enterococcal isolates in this study may be part of endogeneous flora or pathogens in the sampled animals (McGowan et al., 2006; Namet al., 2010).

The $97.89 \%$ enterococcal prevalence in this study is higher when compared with $91,79,73$ and $61.4 \%$ enterococcal isolation prevalence reported in faecal samples of 96 food animals in Tunisia (Klibi et al., 2014), 305 poultry products in The Netherlands (Van Den Braak et al., 1998), 22 and 57 beef samples in USA (McGowan et al., 2006) and Poland (Rozanska et al., 2015), respectively. It is also higher when compared with enterococcal isolation prevalence reported in 232 Tibetan pigs (Li et al., 2014), 275 minced beef samples in Germany (Klein et al., 1998), 362 environmental streptococci isolated from cases of bovine mastitis in USA (Rossito et al., 2002), 636 raw meat samples in Italy (Pesavento et al., 2014), 112 food of animal origin in Poland (Chajęcka-Wierzchowska et al., 2012) and 343 retail chicken meat in USA (Kilonzo-Nthenge et al., 2015), respectively. But it is however lower when compared with $100 \%$ enterococcal isolation prevalence reported in faecal samples of 35 and 39 healthy cattle in USA (Anderson et al., 2008) and Tunisia (Klibi et al., 2014), 262 samples of ground beef in USA (Hayes et al., 2003) and 260 samples of food of animal origin in Czech Republic (Krocko et al., 2011), respectively. The differences in enterococcal separation prevalence in these studies, reflects variation in rate of enterococcal colonization, meat contamination, number of samples processed, health status of sampled animals, and the method of enterococcal isolation in the various studies.

The moderate (21.3\%) tetracycline resistance in the present study suggested selection to the drug. This resistance may be due to acquisition of tetracycline resistance genes following use selection pressure (Pesavento et al., 2014). Tetracycline is commonly used in treating bacterial infections of foodproducing animals in Nigeria because of its broad spectrum effect (Ugwu et al., 2015a). The 21.3\% resistance to tetracycline in this study is lower when compared with $24.5,45,42.9,35.3$ and $80 \%$ tetracycline resistance reported among faecal enterococcal isolates from dairy cattle in USA (Jackson et al., 2010), beef cattle in Lithuania (Ruzauskas et al., 2009), healthy beef and dairy cattle in USA (Anderson et al., 2008), food of animal origin in Italy (Pesavento et al., 2014) and poultry products in Czech Republic (Kolar et al., 2002), respectively. McGowan et al. (2006), Krocko et al. (2007) and Duckova et al. (2014), Liu et al. (2013), Cetinakaya et al. (2013), and Rozanska et al. (2015) reported 24.3, 56 and 44.4, 92.5, 12 and 74.3\% tetracycline resistance among enterococcal isolates from food of animal origin in USA, Slovakia, China, Turkey and Poland, respectively. Nam et al. (2010) and Li et al. (2014) reported 69.5 and 64.3\% tetracycline resistance among enterococcal isolates from milk of mastitic dairy cattle in Korea, and pigs in Tibet, China, respectively. These results are also lower than that of the present study. However, the $21.3 \%$ tetracycline resistance in the present study is higher than 14.9 and $20.1 \%$ tetracycline resistance reported among enterococcal isolates from food animals in Tunisia (Klibi et al., 2014) and minced meat in Germany (Klein et al., 1998). The varying tetracycline resistance rates may be related to the differences in the use of the drug in food animal production in the study areas.

The low rate $(1.3 \%)$ of ciprofloxacin resistance in this study suggested low selection against the drug. This finding suggested that the isolates may have acquired genes encoding for fluoroquinolones resistance at a low proportion (Werner, 2012). The low fluoroquinolones resistance in this study may be related to the fact that this class of antibacterial agents is not commonly used in food-producing mammals (probably because of their

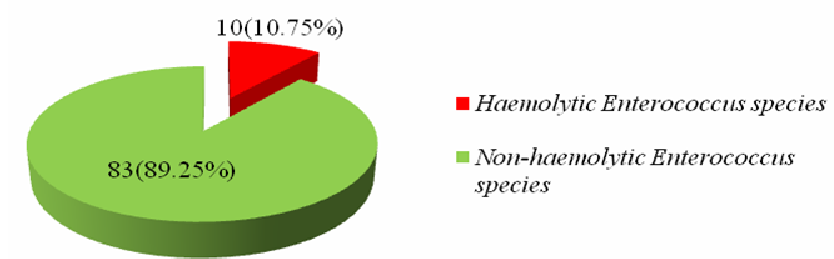

Fig. 1. Prevalence of generic enterococci in healthy beef cattle 
high cost) in the Nigeria (Eze et al., 2013; Ugwu et al., 2015b). The $1.3 \%$ ciprofloxacin resistance in this study is lower when compared with $9.5,8$, and $24.1 \%$ ciprofloxacin resistance reported among faecal enterococcal isolates from cattle in USA (Anderson et al., 2008) and Lithuania (Ruzauskas et al., 2009), and food animals in Tunisia (Klibi et al., 2014) respectively. Hershberger et al. (2005) reported ciprofloxacin resistance of 55 and $45 \%$ among faecal enterococcal isolates form beef and dairy cattle in USA, respectively. Klein et al. (1998), McGowan et al. (2006), Li et al. (2014), Pesavento et al. (2014) and Cetinakaya et al. (2013) reported 2.7, 4.3, 3.6, 7.69 and 33.3\% ciprofloxacin resistance among enterococcal isolates from minced meat in Germany, meat samples in USA, pigs in Tibet China, food of animal origin in Italy and Turkey, respectively. Aarestrup et al. (2002) reported ciprofloxacin resistance which is higher than that observed in this study among enterococci isolated from pigs in Denmark and Sweden. These results are also higher than that of the current study. Variation in ciprofloxacin resistance in these studies may be due to differences in the use of the drug in food-producing animals in the study areas (Hershberger $e t$ al., 2005).

Similarly, low rate (1.3\%) of chloramphenicol resistance in this study suggested that the isolates exerted low selection against the drug. This may be related to the fact that chloramphenicol has long been banned and is no longer used in food animal production in the study area. The 1.3\% chloramphenicol resistance in the present study is similar to $1 \%$ chloramphenicol resistance reported among enterococcal isolates from minced meat in Germany (Klein et al., 1998). But it is lower than 8, 30, 6.41 and $28.6 \%$ chloramphenicol resistance reported among enterococcal isolates from cattle in Lithuania (Ruzauskas et al., 2009), food animals in China (Liu et al., 2013), food of animal origin in Italy (Pesavento et al., 2014), and retail beef in Poland (Rozanska et al., 2015), respectively. Higher chloramphenicol resistance than that of this study, was also reported by Aarestrup et al. (2002) among enterococcal isolates from Danish and Swedish pigs.
Enterococcal resistance to aminoglycoside, particularly to gentamicin and streptomycin, is critical because of their use (in combination with ampicillin) in empirical treatment of enterococcal infections (Klein et al., 1998; Arias et al., 2010; Kristich et al., 2011; Werner, 2012). The CLSI recommended the use of $120 \mu \mathrm{g}$ and $300 \mu \mathrm{g}$ gentamicin and streptomycin discs, respectively, for assessing high level resistance to these drugs (CLSI, 2012). In the hereby experiment, low level resistance of the isolates to the drugs was assessed using $10 \mu \mathrm{g}$ discs for both gentamicin and streptomycin. Low level resistance to these drugs by enterococci suggests possible high level resistance to them (CLSI, 2012). In the current study, high rate $(98.7 \%)$ of resistance to gentamicin (98.7\%) and streptomycin (56\%) suggested that the isolates exerted high selection against aminoglycoside. The result also showed that the isolates exerted higher selection to gentamicin than to streptomycin. This finding suggested that the isolates may have acquired genes encoding for resistance to aminoglycoside (Thal et al., 2000; Werner, 2012). While the present study determined low level aminoglycoside resistance (LLAR), there is a high probability that the isolates would also exhibit high level aminoglycoside resistance (HLAR); enterococcal strains exhibiting HLAR are multidrug-resistant (Rozanska et al., 2015). Nevertheless, the aminoglycoside resistance observed in this study could also be inherent in the isolates, since enteroccoci have been reported to exhibit moderate intrinsic resistance especially to low level aminoglycoside (Barbosa et al., 2009; Kristich et al., 2014). This finding of high rate of LLAR in this study is a cause for concern, because, an aminoglycoside resistance gene confers co-resistance to similar drugs (Febler et al., 2011). The $98.7 \%$ gentamicin resistance observed in this study is higher when compared with 25 and $1.59 \% ; 16.7,30,2.2,1$ and $6.5 \%$ gentamicin resistance reported among enterococcal isolates from food of animal origin in Slovakia (Krocko et al., 2007; Duckova et al., 2014) and Italy (Pesavento et al., 2014); food animal in China (Liu et al., 2013), farm animals in Southwest, Nigeria

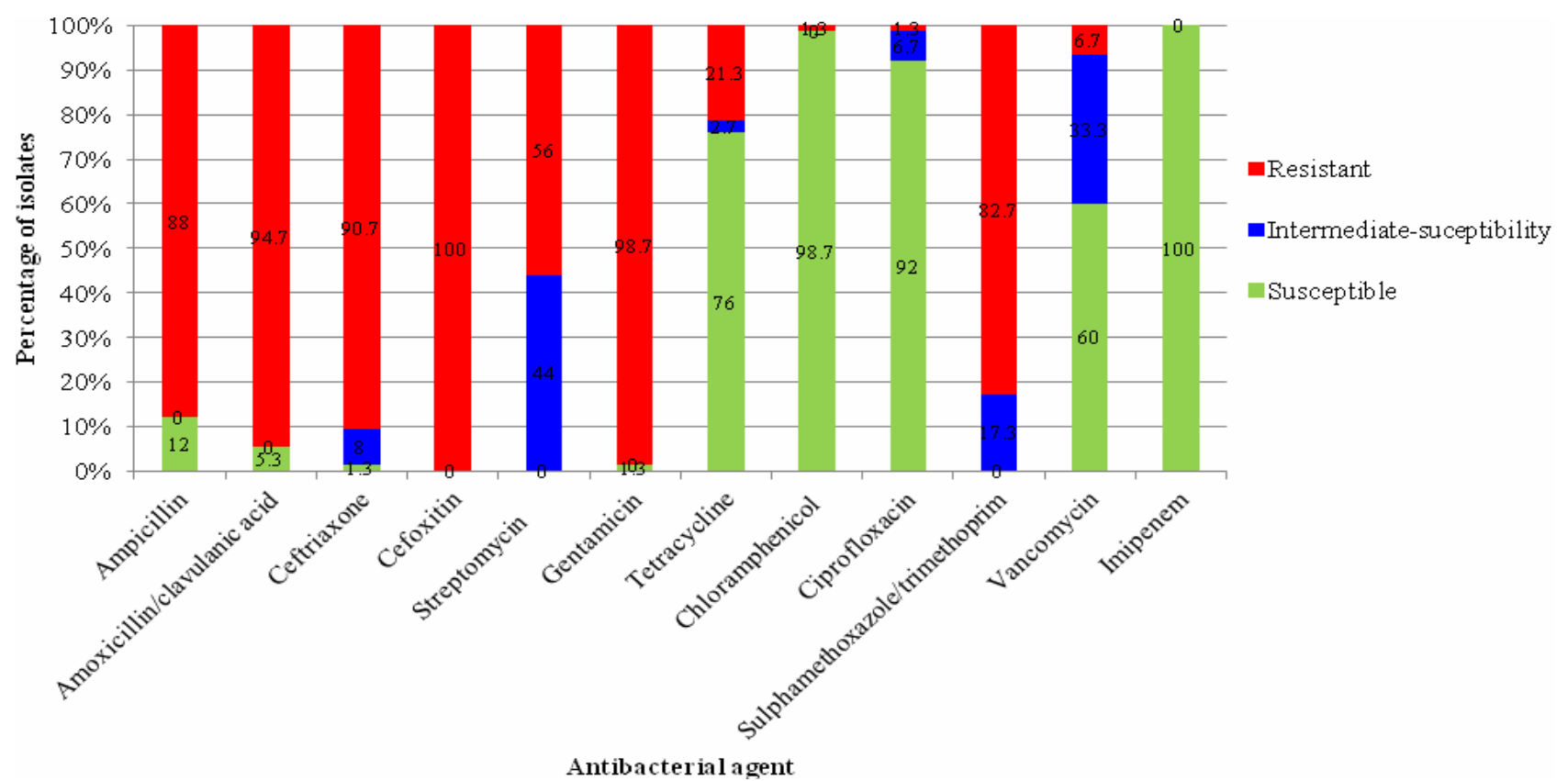

Fig. 2. Antibiogram of 75 enterococcal isolates from healthy beef cattle 
394

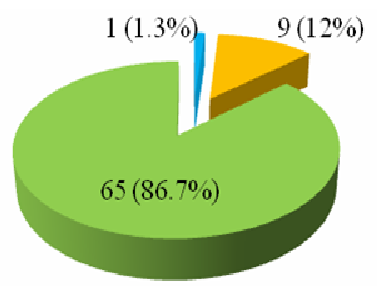

- 1 class of antibacterial agents

$\sim 2$ classes of antibacterial agents

$\square \geq 3$ classes of antibacterial agents

Fig. 3. Number of antibacterial classes to which 75 enterococcal isolates from beef cattle were resistant

(David, 2014), pigs in Denmark (Aarestrup et al., 2002), and meat samples in USA (McGowan et al., 2006), respectively. In this study, the $56 \%$ streptomycin resistance is higher than 14.6 and $40 \%$ streptomycin resistance among enterococcal isolates from meat and cattle reported in USA (McGowan $e t$ al., 2006) and Lithuania (Ruzauskas et al., 2009), respectively. Klein et al. (1998), Liu et al. (2013), Klibi et al. (2014) and Rozanska et al. (2015) reported 1, 50.3, 5.7 and 15\% streptomycin resistance among enterococcal isolates from minced meat in Germany, food of animal origin in China, food animals in Tunisia, retail beef in Poland, and pigs in Sweden, respectively. These findings including that of Aarestrup et al. (2002) among enterococcal isolates from Danish pigs are also lower than streptomycin resistance recorded in the present study. Differences in application of these drugs in treatment of infections in the study areas may account for the variation in their resistance. In Nigeria, streptomycin is often combined with penicillin to exert broad-spectrum effect in treatment of food-producing animals (Ugwu et al., 2015b). The high LLAR observed in this study may be a cause for concern because of compromise (if aminoglycosides resistance genes are acquired) that would occur during treatment of enteroccocal infection in humans and animals in the study area (Donabedian et al., 2003).

The CLSI also recommended the use of $6 \mu \mathrm{g} / \mathrm{mL}$ vancomycin supplemented agar or broth for detection of vancomycin-resistant enterococci (VRE) (CLSI, 2012). Low level vancomycin resistance, a presumptive test for vancomycin resistance, was determined in the hereby experiment using $5 \mu \mathrm{g}$ vancomycin disc. Demonstrable vancomycin resistance (6.7\%) in this study suggested selection against the drug. This suggested that the isolates possibly acquired and haboured vancomycin resistance genes (VRGs). Although the isolates were not confirmed to be VRE, this finding is critical because vancomycin is regarded as last-line of defense against many bacterial pathogens, especially ampicillin/aminoglycoside-resistant enterococci (McDonald et al., 1997; Kolar et al., 2002; Li et al., 2014). The $6.7 \%$ vancomycin resistance in this study is higher than 3.53 and $2.9 \%$ vancomycin resistance among enterococcal isolates from food of animal origin and retail beef reported in Italy (Pesavento et al., 2014) and Poland (Rozanska et al., 2015), respectively. But it is lower when compared with 8,17 and $7.49 \%$ vancomycin resistance among enterococcal isolates from cattle, food of animal origin and pigs reported in Lithuania (Ruzauska et al., 2009), Slovakia (Duckova et al., 2014) and Denmark (Aarestrup et al., 2002), respectively. Variation in resistance rates to aminoglycosides and glycopeptide (vancomycin) in these studies may be due to differences in usage of the drugs in the study areas and/or concentration (whether low or high level) of the drugs used in the various studies.

The high rate $(82.7 \%)$ of sulphamethoxazole/ trimethoprim resistance in this study suggested high selection against the drug. This high potentiated sulfonamide resistance may be due to extensive use of the drug (because of

Table 1. Resistance patterns exhibited by 75 enterococcal isolates from beef cattle

Keys: AMP-Ampicillin, AMC-Amoxicillin/clavulanic acid, STP-Streptomycin, GEN-Gentamicin, CEF-Cefoxitin, CTR-Ceftriaxone, CIP-Ciprofloxacin, TETTetracycline, CHL-Chloramphenicol, VAN-Vancomycin, IMP-Imipenem, SXT-Sulphamethoxazole/trimethoprim

\begin{tabular}{|c|c|c|c|}
\hline $\mathrm{S} / \mathrm{N}$ & Resistance pattern & Frequency & Percentage \\
\hline 1. & GEN-CEF-CTR-SXT & 1 & 1.33 \\
\hline 2. & AMP-GEN-CEF-CTR & 1 & 1.33 \\
\hline 3. & AMP-AMC-GEN-CEF-SXT & 1 & 1.33 \\
\hline 4. & AMP-AMC-STP-GEN-CEF-CTR-TET-CHL-SXT & 1 & 1.33 \\
\hline 5. & GEN-CEF-SXT & 1 & 1.33 \\
\hline 6. & AMC-GEN-CEF-CTR-CIP-TET-SXT & 1 & 1.33 \\
\hline 7. & AMP-AMC-GEN-CEF-CTR-VAN-SXT & 1 & 1.33 \\
\hline 8. & AMP-GEN-CEF-SXT & 1 & 1.33 \\
\hline 9. & AMP-AMC-GEN-CEF-CTR-TET & 1 & 1.33 \\
\hline 10. & AMP-AMC-CEF-CTR & 1 & 1.33 \\
\hline 11. & AMP-AMC-STP-GEN-CEF-CTR & 2 & 2.7 \\
\hline 12. & AMC-S-GEN-CEF-CTR-SXT & 2 & 2.7 \\
\hline 13. & AMP-AMC-STP-GEN-CEF-SXT & 2 & 2.7 \\
\hline 14. & AMP-AMC-STP-GEN-CEF-CTR-TET-VAN & 2 & 2.7 \\
\hline 15. & AMC-GEN-CEF-SXT & 2 & 2.7 \\
\hline 16. & AMC-GEN-CEF-CTR-TET-SXT & 2 & 2.7 \\
\hline 17. & AMP-AMC-STP-GEN-CEF-CTR-VAN-SXT & 2 & 2.7 \\
\hline 18. & AMP-AMC-GEN-CEF-CTR-TET-SXT & 3 & 4 \\
\hline 19. & AMP-AMC-GEN-CEF-CTR & 6 & 8 \\
\hline 20. & AMP-AMC-STP-GEN-CEF-CTR-TET-SXT & 6 & 8 \\
\hline 21. & AMP-AMC-GEN-CEF-CTR-SXT & 11 & 14.7 \\
\hline \multirow[t]{2}{*}{22.} & AMP-AMC-STP-GEN-CEF-CTR-SXT & 25 & 33.3 \\
\hline & Total & 75 & 100 \\
\hline
\end{tabular}


its broad-spectrum effect) in food animal production in Nigeria. Acquisition of genes encoding resistance to potentiated sulfonamide may be the cause of this high sulphamethoxazole/trimethoprim resistance observed in this study (Werner, 2012).

The $82.7 \%$ sulphamethoxazole/trimethoprim resistance in this study is lower than $100 \%$ sulphamethoxazole/trimethoprim resistance among enterococcal isolates from food animals reported in Tunisia (Klibi et al., 2014).

Resistance of enterococci to $\beta$-lactams, particularly ampicillin, is important because they are critical in treatment of enterococcal infections (Klein et al., 1998, Kolar et al., 2002; Kristich et al., 2014; Arias et al., 2010). High rate (88\%) of ampicillin resistance in this study suggested high selection against the drug. The high ampicillin resistance also suggested that the isolates may have produced $\beta$-lactamases (major mechanism of $\beta$-lactam resistance) which hydrolysed the $\beta$-lactam ring of the drug to penicilloic acid (Livermore and Brown, 2001; Werner, 2012; Urmunova, 2015). The isolates may also have exerted resistance to the ampicillin by changing their cell wall permeability, expressing active efflux pump, gene mutation and/or altered penicillin binding protein (PBP) receptors, a well-known intrinsic (natural) $\beta$ lactam resistance mechanism in enterococci (Livermore and Brown, 2001; Kak and Chow, 2002; Kristich et al., 2014; Li et al., 2014; Urmunova, 2015). The high ampicillin resistance may be a result of selective pressure due to inappropriate use of $\beta$-lactams (probably because they are cheap) in Nigeria (Chah and Nweze, 2001; Ugwu et al., 2015b). High rate (94\%) of resistance to amoxicillin/clavulanic acid (a $\beta$-lactam$\beta$-lactamase inhibitor) in this study suggested that the isolates produced AmpC $\beta$-lactamases (cephalosporinases), the major mediators of resistance to $\beta$-lactam- $\beta$-lactamase inhibitors (Ben Sallem et al., 2012). Other mechanisms of resistance to $\beta$-lactam- $\beta$-lactamase inhibitors that the isolates might have exhibited include: hyper-production of class A $\beta$-lactamases (i.e. TEM-1 or SHV-1), production of class $\mathrm{D}$ plasmidmediated enzyme, chromosomal or plasmidic class $C \beta$ lactamase, and modification of outer membrane permeability (Chaibi et al., 1999; Dwarz and Bonomo, 2010). The 88\% ampicillin resistance in this study is higher when compared with $1.2,4.2,9.52,2.24$ and $16.7 \%$ ampicillin resistance recorded among enterococcal isolates from Tibetan pigs (Li $e t$ al., 2014), food animals in China (Liu et al., 2013), and food of animal origin in Slovakia (Duckova et al., 2014), Italy (Pesavento et al., 2014) and Turkey (Cetinakaya et al., 2013), respectively. The result also contrasts Klibi et al. (2014) and Klein et al. (1998) who did not detect ampicillin resistance among enterococcal isolates from food animals in Tunisia and minced meat in Germany, respectively.

The high $\beta$-lactam resistance rates among isolates (which are non clinical strains) in this study, is not in agreement with Lopes et al. (2005) and Pesavento et al. (2014) who stated that resistance of enterococci to $\beta$ lactam antibiotics seems to be associated with clinical strains. The finding of higher ampicillin resistance in this study is worrisome, because, the use of extended-spectrum $\beta$-lactams (ESBL) would further be resorted for use in treating enterococcal infections in foodproducing animals in the study area. However, the 94\% amoxicillin/clavulanic acid resistance in the current study is higher when compared with $0.32 \%$ amoxicillin/clavulanic acid resistance among enterococcal isolates from food of animal origin reported in Italy (Pesavento et al., 2014).

High rate of resistance to ceftriaxone (90.7\%) and cefoxitin $(100 \%)$ in this study suggested production of extended-spectrum $\beta$-lactamases (ESBLs) (Geser et al., 2012). Ceftriaxone and cefoxitin are oxyimino-cephalosporins (extended-spectrum- $\beta$-lactams [ESBL]) whose resistance is mediated by ESBLs (Carattoli, 2008; Geser et al., 2012). Confirmation of ESBLs production is done using ceftriaxone plus clavulanic acid disc synergy test (CLSI, 2012). Single discs of these drugs were used in the hereby experiment. Thus, the finding of high ESBL-resistance in this study, suggested that the isolates acquired genes encoding for ESBLs in high proportion. This may be a result of inappropriate use of ESBL in human and veterinary medicine in Nigeria. Possible sources of the ESBLs-encoding genes were organisms which contaminated ingested feed, vegetation, drinking water and/or cattle environment (Silva et al., 2012; Klibi et al., 2014). It is also possible that because of resistance to $\beta$-lactams (e.g. ampicillin and amoxicillin/clavulanic acid), ESBL were used in treating previous infection(s) in the sampled animals. The finding of high ESBL-resistance in this study is a cause for real concern because ESBL-resistant enterococci could rapidly spread ESBL-encoding genes to bacteria flora in human consumers of the beef, owing to location of ESBLs genes on highly promiscuous mobile genetic elements (Ewers et al., 2012). Moreover, it is known that ESBL-resistant organisms exhibit co-resistance to other classes of antibacterial agents including aminoglycosides, fluoroquinolones, tetracyclines, phenicols, and potentiated sulfonamides (Gniadowski, 2001; Coque et al., 2008; Geser et al., 2012). Thus, resistance to drugs belonging to these classes of antibacterial agents in this study may also be mediated by ESBLs which the enterococcal isolates might have produced. Therefore, the presence of ESBL-resistant (multidrugresistant) enterococci in the sampled animals is worrisome because it adversely impacts the food chain and poses a huge threat to the health of consumers of beef and associated products from these cattle. Moreover, the overall consequence of high ESBL-resistance rate observed in this study is, if unchecked, the use of carbapenem may be resorted for use in production of food-producing animals in the study area. The $100 \%$ resistance to ceftriaxone in this study is higher when compared with $35.4 \%$ ceftriaxone resistance among enterococcal isolates from minced meat reported in Germany (Klein et al., 1998).

Interestingly, none of the isolates to 3 or more antibacterial agents tested in this study exhibited demonstrable resistance to carbapenem (imipinem), the last resort drug for the treatment of multidrug-resistant bacteria (Abraham et al., 2014). This finding suggested that carbapenem have not been abused in food animal production in Nigeria. Howbeit, this status (non-carbapenem resistance in enterococcal isolates from cattle) should be maintained; because, the emergence of carbapenem-resistant enterococcal strains in food-producing animals, would definitely result in rapid dissemination of these organisms to the public due to unhygienic animal slaughter practices in Nigeria. Consequently, untreatable and highly fatal infections would emerge since carbapenem-resistant organisms are superbugs resistant to all known therapeutic agents 
396

(Johnson and Woodford, 2012; Abraham et al., 2014).

In this study, resistance of $65(86.7 \%)$ isolates coupled with $22(100 \%)$ multidrug resistance patterns, further suggested that high numbers of enterococci colonizing cattle slaughtered in the study area are multidrug resistant strains (Tenover, 2006; Rozanska et al., 2015). This finding corroborates previous reports that most enterococcal isolates from food-producing animals exhibit multidrug resistance (Ruzauskas et al., 2009). This multidrug resistance exhibited by the isolates could be due to acquisition of multidrug resistance genes (such as ESBLs, fluoroquinolones and vancomycin resistance genes) and also to intrinsic resistance to some antibacterial agents (Paulsen et al., 2003; Fischer and Philips, 2009; Kristich et al., 2014). The $86.7 \%$ multidrug resistance in this study is lower than $100 \%$ multidrug resistance among enterococcal isolates from food reported animals in Canada (Trembley et al., 2011). But it is higher than 18.5, 52 and $52.6 \%$ multidrug resistance among enterococcal isolates reported in Tunisia (Klibi et al., 2014), Poland (Rozanska et al., 2015) and Korea (Nam et al., 2010), respectively.

\section{Conclusions}

This study has shown that a sizeable percentage (97.89\%) of cattle slaughtered in Nigeria was positive of multidrug-resistant enteroccoci and prove that cattle are potential reservoirs and disseminators of multidrugresistant enterococci. These organisms are reservoirs of multiple resistance genes and transfer them to bacteria flora of humans when consumed together with meat and meat products. Therefore, their presence in slaughtered cattle portends huge adverse impact on the food chain and poses serious health threat to the consumers of the beef and associated products from the cattle. However, further studies to deduce high level vancomycin and aminoglycosides resistance, and the antimicrobial resistance genes harboured by the isolates is recommended.

\section{References}

Aarestrup FM, Agerso Y, Gerner-Smidt P, Madsen M, Jensen L (2000). Comparison ofantimicrobial resistance phenotypes and resistance genes in Enterococcus faecalis and Enterococcus faecium from humans in the community, broilers, and pigs in Denmark. Diagnostic Microbiology and Infectious Diseases 37:127-137.

Aarestrup FM, Hasman H, Jensen L, Moreno M, Herrero IA, Domínguez L, Finn M, Franklin A (2002). Antimicrobial resistance among enterococci from pigs in three European countries. Applied and Environmental Microbiology 68(8):4127-4129.

Abraham S, Wong HS, Turnidge J, Johnson JR, Trott DJ (2014). Carbapenemase-producing bacteria in companion animals: a public health concern on the horizon. Journal of Antimicrobial Chemotherapy doi:10.1093/jac/dkt518.

Amaechi N (2015). Plasmid profile and antimicrobial resistance ratings of enterococci isolates from pigs and poultry birds in Abia State Nigeria. African Journal of Clinical and
Experimental Microbiology 16(1):54-61.

http://dx.doi.org/10.4314/ajcem.v16i2.2.

Amaechi N, Nwankwo IU (2015). Evaluation of prevalence and antimicrobial resistance using enterococci isolates from pigs and poultry and birds in Abia State, Nigeria. International Journal of Current Microbiology and Applied Sciences 4(2):825-833.

Anderson JF, Parrish TD, Akhtar M, Zurek L, Hirt H (2008). Antibiotic resistance of enterococci in American Bison (Bison bison) from a nature preserve compared to that of enterococci in pastured cattle. Applied and Environmental Microbiology 74(6):1726-1730.

Arias CA, Contreras GA, Murray BE (2010). Management of multidrug-resistant enterococcal infections. Clinical Microbiology and Infections 16(6):555-562.

Bager N, Jensen E, Madsen M, Meyling A, Wegener HC (1998). Surveillance of antimicrobial resistance in bacteria isolated from food animals to antimicrobial growth promoters and related therapeutic agents in Denmark. APMIS 106:606-622.

Barbosa J, Ferreira V, Teixeira P (2009). Antibiotic susceptibility of enterococci isolated from traditional fermented meat products. Food Microbiology 26:527-532.

Ben Sallem R, Ben Slama K, Saenz Y, Rojo-Bezares B, Estepa V, Jouini A, Gharsa H, Klibi N, Boudaous A, Torres C (2012). Prevalence and characterization of extended-spectrum beta-lactamase (ESBL)and CMY-2-producing Escherichia coli isolates from healthy food producing animals in Tunisia. Foodborne Pathogens and Disease 9(12):1137-1142.

Beukers AG, Zaheer R, Cook SR, Stanford K, Chaves AV, Ward MP, McAllister TA (2015). Effect of in-feed administration and withdrawal of tylosin phosphate on antibiotic resistance in enterococci isolated from feed lot steers. Frontiers in Microbiology 6(483):doi: 10.3389/fmicb.2015.00483.

Borgen K, Sorum M, Wasteson Y, Kruse H (2001). VanA-type vancomycin-resistant enterococci (VRE) remain prevalent in poultry carcasses 3 years after avoparcin was banned. International Journal of Food Microbiology 28:89-94.

Brtkova A, Filipova M, Drahovska H, Bujdakova H (2010). Characterization of enterococci of animal and environmental origin using phenotypic methods and comparison with PCR based methods. Veterinarni Medicina 3:97-105.

Carattoli A (2008). Animal reservoirs for extended-spectrum betalactamase producers. Clinical Microbiology and Infection 14:117-123.

Çetinakaya F, Elal Muş T, Soyutemiz GE, Çibik R (2013). Prevalence and antibiotic resistance of vancomycin-resistant enterococci in animal originated foods. Turkish Journal of Veterinary and Animal Sciences 37:588-593.

Chah KF, Nweze NE (2001). Antibiotic use in poultry production in Nsukka, Southeast Nigeria. Proceedings of Nigerian Society of Animal Production 26:69-72.

Chaibi EB, Sirot D, Paul G, Labia R (1999). Inhibitor-resistant TEM $\beta$ lactamases: phenotypic, genetic and biochemical characteristics. Journal of Antimicrobial Chemotherapy 43:447-458.

Chajęcka-Wierzchowska W, Zadernowska A, Nalepa B, LaniewskaTrokenheim L (2012). Occurrence and antibiotic resistance of enterococci in ready-to-eat food of animal origin. African Journal of 
Microbiology Research 6(39):6773-6780.

Clinical and Laboratory Standards Institute (CLSI) (2012). Performance standards for antimicrobial susceptibility testing; twenty-second informational supplement M100-S22 32(3):62-78.

Coque TM, Baquero F, Canton R (2008). Increasing prevalence of ESBL producing Enterobacteriaceae in Europe. European Surveillance 13(47):5437-5453.

David OM (2014). Virulence factors and antibiotic resistance of Enterococcus faecalis and Enterococcus gallinarum strains isolated from farm animals in Ado-Ekiti, Nigeria. Wayamba Journal of Animal Science 2014:824831.

Donabedian SM, Thal LA, Hershberger E, Perri MB, Chow JW, Bartlett P, Jones R, Joyce K, Rossiter S, Gay K, Johnson J, Mackinson C, Debess E, Madden J, Angulo F, Zervos MJ (2003). Molecular characterization of gentamicin-resistant enterococci in the United States: evidence of spread from animals to humans through food. Journal of Clinical Microbiology 41:1109-1113.

Ducková V, Čanigová M, Kročko M, Lavová M (2014). Antibiotic susceptibility and biofilm-forming capacity of enterococci isolated from food of animal origin. Medycyna Weterynaryjna 70:36-37.

Dwarz SM, Bonomo RA (2010). Three decades of beta-lactamase inhibitors. Clinical Microbiological Reviews 23(1):160-201.

Ewers C, Bethe A, Semmler T, Guenther S, Wieler LH (2012). Extended-spectrum $\beta$-lactamase-producing and AmpC-producing Escherichia coli from livestock and companion animals, and their putative impact on public health: a global perspective. Clinical Microbiology and Infection 18:646-655.

Eze E, Nwakeze E, Oji A, Ejikeugwu C, Iroha I (2013). Microbiological investigation of Escherichia coli isolates from cloacal and feacal swabs of broiler chickens for extended- spectrum beta-lactamase (ESBL) enzymes. Journal of Pharmacy and Biological Sciences 7(5):96-99.

Febler AT, Kadlec K, Hassel M, Hauschild T, Eidam C, Ehricht R, Monecke S, Schwarz S (2011). Characterization of methicillinresistant Staphylococcus aureus isolates from food and food products of poultry origin in Germany. Applied and Environmental Microbiology 77(20):7151-7157.

Fisher K, Phillips C (2009). The ecology, epidemiology and virulence of Enterococcus. Microbiology 155:1749-1757.

Geser N, Stephan R, Hachler H (2012). Occurrence and characteristics of extended-spectrum $\beta$-lactamase (ESBL) producing enterobacteriaceae in food producing animals, minced meat and raw milk. BMC Veterinary Research 8:21.

Gniadkowski M (2001). Evolution and epidemiology of extendedspectrum beta-lactamases (ESBLs) and ESBL-producing microorganisms. Clinical Microbiology and Infection 7:597-608.

Hammerum AM, Lester CH, Heuer OE (2010). Antimicrobialresistant enterococci in animals and meat: a human health hazard? Foodborne Pathogen and Diseases 7:1137-1146.

Han D, Unno T, Jang J, Lim K, Lee S, Ko G, Sadowsky MJ, Hur H (2011). The occurrence of virulence traits among high-level aminoglycosides resistant Enterococcus isolates obtained from feces of humans, animals, and birds in South Korea. International Journal of Food Microbiology 144:387-392.

Hayes JR, English LL, Carr E, Wagner DD, Joseph SS (2004). Multiple- antibiotic resistance of Enterococcus spp. isolated from commercial poultry production environments. Applied and Environmental Microbiology 70:6005-6011.

Hayes JR, English LL, Carter PJ, Proescholdt T, Lee KY, Wagner DD, White DG (2003). Prevalence and antimicrobial resistance of Enterococcus species isolated from retail meats. Applied and Environmental Microbiology 69(12):7153-7160.

Hershberger E, Oprea SF, Donabedian SM, Perri M, Bozigar P, Bartlett P, Zervos MJ (2005). Epidemiology of antimicrobial resistance in enterococci of animal origin. Journal of Antimicrobial Chemotherapy 55:127-130.

Huys G, D’Haene K, Collard JM, Swings J (2004). Prevalence and molecular characterization of tetracycline resistance in Enterococcus isolates from food. Applied and Environmental Microbiology 70:1555-1562.

Iweriebor BC, Obi LC, Okoh AI (2015). Virulence and antimicrobial resistance factors of Enterococcus spp. isolated from fecal samples from piggery farms in Eastern Cape, South Africa BMC Microbiology 15:136 doi:10.1186/s12866-015-0468.

Jackson CR, Lombard JE, Dargatz DA, Fedorka-Cray PJ (2010). Prevalence, species distribution and antimicrobial resistance of enterococci isolated from US dairy cattle. Letters in Applied Microbiology 52(1):41-48.

Johnson AP, Woodford N (2012). Global spread of antibiotic resistance: the example of New Delhi metallo-beta-lactamase (NDM)-mediated carbapenem resistance. Journal of Medical Microbiology 62:499-513.

Kak V, Chow JW (2002). Acquired antibiotic resistances in enterococci. In: Gilmore MS (Ed). The enterococci: pathogenesis. Molecular biology and antibiotic resistance. Washington DC American Society for Microbiology pp 355-383.

Kasimoglu-Dogru A, Gencay YE, Ayaz ND (2010). Prevalence and antibiotic resistance profiles on Enterococcus species in chicken at slaughter level: absence of van $A$ and $\operatorname{vanB}$ genes in $E$. faecalis and $E$. faecium. Research in Veterinary Science 89:153-158.

Kaszanyitzky EJ, Tenk M, Ghidan A, Fehervari GY, Papp M (2007). Antimicrobial susceptibility of enterococci strains isolated from slaughter animals on the data of Hungarian resistance monitoring system from 2001 to 2004. International Journal of Food Microbiology 115:119-123.

KempfI, Hellard G, Perrin-Guyomard A, Gicquel-Bruneau M, Sanders P, Leclercq R (2008). Prevalence of high-level vancomycin-resistant enterococci in French broilers and pigs. International Journal of Antimicrobial Agents 32:459-464.

Kilonzo-Nthenge A, Brown A, Nahashon SN, Long D (2015). Occurrence and antimicrobial resistance of enterococci isolated from organic and conventional retail chicken. Journal of Food Protection 78(4):760-766.

Klein G, Pack A, Reuter G (1998). Antibiotic resistance patterns of enterococci and occurrence of vancomycin-resistant enterococci in raw minced beef and pork in Germany. Applied and Environmental Microbiology 64:1825-1830.

Klibi N, Aouini R, Borgo F, Ben Said L, Ferrario C, Dziri R, Boudabous A, Torres C, Ben Slama K (2014). Antibiotic resistance and virulence of faecal enterococci isolated from food-producing 
398

animals in Tunisia. Annals of Microbiology 65(2):695-702.

Kolář M, Pantůček R, Bardoň J, Vágnerová I, Typovská $H$, Doškař J, Válka I (2002). Occurrence of antibiotic-resistant strains isolated in poultry. Veterinary Medicine Czech 47:5259.

Koluman A, Akan LS, Cakiroglu FP (2009). Occurrence and antimicrobial resistance of enterococci in retail foods. Food Control 20:281-283.

Kristich CJ, Rice LB, Arias CA (2014). Enterococcal infection treatment and antibiotic resistance. In: Gilmore MS, Clewell DB, Ike Y, Shankar N (Eds). Enterococci: from commensals to leading causes of drug resistant infection [Internet]. Boston: Massachusetts eye and ear infirmary http://www.ncbi.nlm.nih.gov/pubmed/24649502.

Krocko M, Čanigova M, Duckova V (2007). Occurrence, isolation and antibiotic resistance of Enterococcus species isolated from raw pork, beef and poultry. Journal of Food and Nutrition Research 46(2):91-95.

Kročko M, Čanigová M, Ducková V, Artimová A, Bezeková J, Poston J (2011). Antibiotic resistance of Enterococcus species isolated from raw foods of animal origin in South West part of Slovakia. Czech Journal of Food Science 29(6):654-659.

Kuhn I, Iversen A, Burman LG, Olsson-Liljequist B, Franklin A, Finn M, Aarestrup F, Seyfarth AM, Blanch AR, Taylor H, Caplin J, Moreno MA, Dominguez L, Mollby R (2000). Epidemiology and ecology of enterococci, with special reference to antibiotic resistant strains, in animals, humans and the environment: example of an ongoing project within the European research programme. International Journal of Antimicrobial Agents 14:337-342.

Laxminarayan R, Duse A, Wattal A, Zaidi AKM, Wertheim HFL, Sumpradit N, Vlieghe E, Hara GL, Gould IM, Goossens H, Greko C, So AD, Bigdeli M, Tomson G, Woodhouse W, Ombaka E, Peralta AQ, Qamar FN, Mir F, Kariuki S, Bhutta ZA, Coates A, Bergstrom R, Wright GD, Brown ED, Cars O (2013). Antibiotic resistance - the need for global solution. The Lancet infectious diseases 13(12):1057-1098.

Li P, Wu D, Liu K, Suolang S, He T, Liu X, Wu C, Wang Y, Lin D (2014). Investigation of antimicrobial resistance in Escherichia coli and enterococci isolated from Tibetan pigs. PLoS ONE 9(4): e95623 doi:10.1371/journal.pone.0095623.

Liu Y, Liu K, Lai J, Wu CM, Shen JZ, Wang Y (2013). Prevalence and antimicrobial resistance of Enterococcus species of food animal origin from Beijing and Shandong Province, China. Journal of Applied Microbiology 114(2):555-563.

Livermore DM, Brown DF (2001). Detection of beta-lactamase mediated resistance. Journal of Antimicrobial Chemotherapy 48:59-64.

Lopes MFS, Ribeiro T, Abrantes M, Marques JJF, Tenreiro R, Crespo MTB (2005). Antimicrobial resistance profiles of dairy and clinical isolates and type strains of enterococci. International Journal of Food Microbiology 103:191-198.

Manolopoulou E, Sarantinopoulos P, Zoidou E, Aktypis A, Moschopoulou E, Kandarakis IG, Anifantakis EM (2003). Evolution of microbial populations during traditional Feta cheese manufacture and ripening. International Journal of Food Microbiology 82:153-161.

Martins E, Novais C, Freitas AR, Dias AR, Ribeiro TG, Antunes P, Peixe L (2015). Filling the map for antimicrobial resistance in sub-Saharan Africa: ampicillin-resistant Enterococcus from non-clinical sources in Angola. Journal of Antimicrobial Chemotherapy doi:10.1093/jac/dkv172.

McDonald LC, Kuerhnert MJ, Tenover FC, Jarvis WR (1997). Vancomycin resistant enterococci outside the health-care setting: prevalence, sources and public health implications. Emerging and Infectious Disease 3:261-264.

McGowan LI, Jackson CR, Barrett JB, Hiott LM, Fedorka-Cray PJ (2006). Prevalence and antimicrobial resistance of enterococci isolated from retail fruits, vegetables, and meats. Journal of Food Protection 69:2976-2982.

Morrison BJ, Rubin JE (2015). Carbapenemase producing bacteria in the food supply escaping detection. PloS One doi:10.1371/journal.pone.0126717.

Nam HM, Lim SK, Moon JS, Kang HM, Kim JM, Jang KC, Kim JM, Kang MI, Joo YS, Jung SC (2010). Antimicrobial resistance of enterococci isolated from mastitic bovine milk samples in Korea. Zoonoses Public Health 57(7-8):59-64.

Paulsen IT, Banerjei L, Myers GSA, Nelson KE, Seshadri R, Read TD, ... Tettelin H (2003). Role of mobile DNA in the evolution of vancomycin-resistant Enterococcus faecalis. Science 299(5615):2071-2074.

Pesavento G, Calonico C, Ducci B, Magnanini A, Nostro AL (2014). Prevalence and antibiotic resistance of Enterococcus spp. isolated from retail cheese, ready-to-eat salads, ham, and raw meat. Food Microbiology 41:1-7.

Ristori CA, Rowlands REG, Bergamini AMM, Lopes GISL, de Paula AMR, de Oliveira MA, Marisa Lima MJC, Tegani LS, Watanabe AH, Jakabi M, Zanella RC (2012). Prevalence and antimicrobial susceptibility profile of Enterococcus spp isolated from frozen chicken carcasses. Revista do Instituto Adolfo Lutz, São Paulo 71(2):237-243.

Rossitto PV, Ruiz L, Kikuch Y, Glenn K., Luiz K, Watts JL, Cullor JS (2002). Antibiotic susceptibility patterns for environmental streptococci isolated from bovine mastitis in Central California dairies. Journal of Dairy Science 85:132-138.

Różańska H, Lewtak-Piłat A, Osek J (2015) Antimicrobial resistance of Enterococcus faecalis isolated from meat. Bulletin of Veterinary Institute in Pulawy 59:229-233.

Ruzauskas M, Virgailis M, Siugzdinine R, Suziedeliene E, Seputiene V, Dagelavicius R, Zienius D, Sengaut J, Pavilonis A (2009). Antimicrobial resistance of Enterococcus spp. isolated from livestock in Lithuania. Veterinarski Arhiv 79(5):439-449.

Seo KS, Lim JY, Yoo HS, Bae WK, Park YH (2005). Comparison of vancomycin-resistant enterococci isolates from human, poultry and pigs in Korea. Veterinary Microbiology 106:225233.

Shin E, Hong H, Ike Y, Park YH, Cho DT, Lee Y (2006). VanBVanA incongruent VRE isolated from animals and humans in 1999. Journal of Microbiology 44:453-456. 
Silva N, Igrejas G, Gonçalves A, Poeta P (2012). Commensal gut bacteria: distribution of Enterococcus species and prevalence of $E$. coli phylogenetic groups in animals and humans in Portugal. Annals of Microbiology 62:449-459.

Sood S, Malhotra M, Das BK, Kapil A (2008). Enterococcal infections and antimicrobial resistance. Indian Journal of Medical Research 128(2):111-121.

Stobberingh E, van den Bogaard A, London N, Driessen C, Top J, Willems R (1999). Enterococci with glycopeptide resistance in turkeys, turkey farmers, turkey slaughterers, and sub (urban) residents in the south of the Netherlands: evidence for transmission of vancomycin resistance from animals to humans? Antimicrobial Agents and Chemotherapy 43:2215-2221.

Šustáčková A, Nápravníková E, Schlegelová J (2004). Antimicrobial resistance of Enterococcus spp. isolates from raw beef and meat products. Folia Microbiologica 49:411-417.

Tenover FC (2006). Mechanisms of antimicrobial resistance in bacteria. American Journal of Medicine 119(6):S3-S10.

Tenover FC, McDonald LC (2005). Vancomycin-resistant staphylococci and enterococci: epidemiology and control. Current Opinion in Infectious Diseases 18:300-305.

Thal L, Hershberger E, Jones R, Joyce K, Hill B, Marano N, Rossiter S, Clark N, Tenover F, Gilbert L, Franko E, Steiner C, Johnson J, DeBess E, Madden J, Zervos M (2000). Molecular mechanism of gentamicin resistance among enterococci isolated from humans, food animals, meat and poultry. $40^{\text {th }}$ Interscience Conference on Antimicrobial Agents and Chemotherapy. Toronto, Canada, September 2000.

Tremblay CL, Letellier A, Quessy S, Boulianne M, Daignault D, Archambault M (2011). Multiple-antibiotic resistance of Enterococcus faecalis and Enterococcus faecium from cecal contents in broiler chicken and turkey flocks slaughtered in Canada and plasmid colocalization of tet $\mathrm{O}$ and erm $\mathrm{B}$ genes. Journal of Food Protection 74:1639-1648.

Ugwu IC, Anyanwu MU, Ugwu CC, Okoro JN (2015a). Isolation and detection of methicillin-resistant staphylococci in healthy broilers in Nsukka Southeast, Nigeria. Notulae Scientia Biologicae 7(1):20-25.

Ugwu IC, Anyanwu MU, Ugwu CC, Ugwuanyi OW (2015b). Prevalence and antibiogram of generic extended-spectrum betalactam-resistant enterobacteria in healthy pigs. Notulae Scientia
Biologicae 7(3):272-280.

Urmunova V (2015) Extended spectrum beta-lactamase producing animal enterobacteriaceae isolates as potential risk to public health. Revue Medicine Veterinaire 166:7-8:192-207.

Van Den Braak N, Van Belkum A, Van Keulen M, Vliegenthart J, Verbrugh HA, Endtz HP (1998). Molecular characterization of vancomycin resistant enterococci from hospitalized patients and poultry products in The Netherlands. Journal of Clinical Microbiology 36:1927-1932.

Vergis EN, Hayden MK, Chow JW, Snydman DR, Zervos MJ, Linden PK, Wagener MM, Schmitt B, Muder RR (2001). Determinants of vancomycin resistance and mortality rates in enterococcal bacteremia. Annals of Internal Medicine 135:484492.

Werner G (2012). Current trends of emergence and spread of vancomycin-resistant enterococci. http://edoc.rki.de/oa/ articles/reHFVRZQIQpo2/PDF/27bPs NUnqX4Gw.pdf

Werner G, Coque TM, CMAP Franz, Grohmannd E, Hegstade K, Jenseng L, van Schaikh W, Weaveri K (2013). Antibiotic resistant enterococci - tales of a drug resistance gene trafficker. International Journal of Medical Microbiology 6:360-379.

World Health Organization (WHO) (2014). Antimicrobial resistance global report on surveillance. Retrieved 2015 January 12 from http://www.who.int/drugresistance/documents/ surveillancereport/en/. 